九州大学学術情報リポジトリ

Kyushu University Institutional Repository

Optimal Number of Field Surveys in a Year to Assess the Diversity of Leafhopper and Butterfly

Kamitani, Satoshi

https://doi.org/10.5109/2659

出版情報: ESAKIA. 42，pp.33-39，2002-03-31. Entomological Laboratory，Faculty of Agriculture， Kyushu University

バージョン :

権利関係 : 


\title{
Optimal Number of Field Surveys in a Year to Assess the Diversity of Leafhopper and Butterfly*
}

\author{
Satoshi KAMITANI \\ Entomological Laboratory, Faculty of Agriculture, \\ Kyushu University, Fukuoka, 812-8581 Japan
}

\begin{abstract}
By using leafhopper and butterfly as bioindicators, computer simulation was performed to determine (1) how many times we must survey in a year to clarify true species richness, (2) to what extent we can clarify the true species richness by 3-time field surveys in a year, and (3) in which combination of months we can obtain the maximum number of species. I found that about $90 \%$ of the true species richness of leafhopper and butterfly could be clarified by 3-time field surveys. To assess the true species richness, we have to survey at least 5.4 times for leafhopper and 5.5 times for butterfly. In an optimal schedule, surveys for leafhopper should be performed in May, June, July, August, September, and December, of which the last one is the key month. For butterfly, we should survey in April, May, June, July (key month), August, and September.
\end{abstract}

Key words: biodiversity, true species richness, Lepidoptera, Cicadellidae, optimal schedule.

\section{Introduction}

Species richness is one of the most important traits of biodiversity (Harin and Hawksworth, 1996), but assessing true species richness is no easy task because extraordinarily intensive field surveys are needed. Therefore, determination of an optimal sampling intensity is required to assess true species richness. In Japan, however, the optimal intensity has never been estimated for other insect groups than butterfly. The optimal number of field surveys for Japanese butterfly diversity was roughly estimated to be six times a year (Yamamoto, 1998).

\footnotetext{
* Contribution from the Entomological Laboratory, Faculty of Agriculture, Kyushu University,
} 
The sampling intensity for general environmental assessment is strongly affected by its purpose and cost. In comparison with the assessment of true species richness, the number of field surveys is usually reduced in the general environmental assessment, hence we cannot grasp of true biodiversity. In Japan, field surveys for the assessment have been performed in spring, summer, and autumn as a custom without any proper reason. As a rule, the three times of field surveys in a year have been required to perform in the almost same seasons of the previous year.

The 6-time field surveys that were proposed by Yamamoto (1998) for butterfly diversity seem to be empirical. We always face a difficulty in determining the number of field surveys and the combination of months to be surveyed because there are enormous combinations of months. In order to overcome the difficulty, in this study I intended to use a method of computer simulation and to focus on the following three points: (1) how many times we must survey to clarify true species richness in a year, (2) to what extent we can clarify the true species richness by 3 -time field surveys in a year, and (3) in which combination of months we can obtain the maximum number of species.

The study of herbivore species richness gives us useful information for better understanding of biodiversity because they are associated with plant species and attacked by various natural enemies. In this study, I used butterfly and leafhopper as bioindicators. Butterfly has been used as one of convenient bioindicators because species of butterfly can be more easily identified, even in the air, than other insect groups, but the activity of butterfly is strongly influenced by weather conditions. In contrast, leafhopper has seldom been used as a bioindicator, but it is more abundant in the number of species and individuals than butterfly and the activity of leafhopper is not severely influenced by weather conditions.

I wish to express gratitude to Prof. J. Yukawa and Assoc. Prof. O. Tadauchi (Entomological Laboratory, Kyushu University) for their directions. My thanks are due to Mr. A. Matsunaga and Miss. A. Saito for their assistance to my surveys.

\section{Materials and Methods}

Field survey: Local species diversity of leafhoppers (Cicadellidae) was surveyed at three census fields in Fukuoka Prefecture, Kyushu, Japan; Motooka (Fukuoka City), Ino (Hisayama Town), and Konomiyama (Fukuma Town) (Table 1). The census field at Motooka and Ino was divided into five and two sites, respectively. All the census fields are largely covered with a secondary forest dominated by evergreen Quercus glauca Thunb. ex. Murray. Field surveys were performed once a month from March to December in 2000 and 2001. At each site, I collected leafhoppers along a 0.5 to $1.0 \mathrm{~km}$ trail by the quantitative sweeping method (Kamitani and Saito, 2001).

In addition to my own collecting data of leafhoppers, I analyzed butterfly species 
Table 1. Study site, subsection, year, month, the length of trail $(\mathrm{km})$, and species richness

\begin{tabular}{|c|c|c|c|c|c|}
\hline site & subsite & year & month & trail & species richness \\
\hline \multicolumn{6}{|l|}{ Butterfly } \\
\hline \multirow[t]{4}{*}{ Aburayama } & & 1994 & Apr. - Nov. & 2.0 & 47 \\
\hline & & 1995 & Apr. - Nov. & 2.0 & 43 \\
\hline & & 1996 & Apr. - Nov. & 2.0 & 46 \\
\hline & & 1997 & Apr. - Oct. & 2.0 & 40 \\
\hline \multicolumn{6}{|l|}{ Leafhopper } \\
\hline \multirow[t]{9}{*}{ Motooka } & R1 & 2000 & May - Aug., Nov. - Dec. & 0.5 & 25 \\
\hline & & 2001 & Mar. - Oct. & 0.5 & 35 \\
\hline & & $2000-01$ & Mar. - Dec. & 0.5 & 39 \\
\hline & $\mathrm{R} 2$ & 2000 & May - Aug., Nov. - Dec. & 0.5 & 25 \\
\hline & & 2001 & Mar. - Oct. & 0.5 & 39 \\
\hline & & $2000-01$ & Mar. - Dec. & 0.5 & 42 \\
\hline & $\mathrm{R} 3$ & 2001 & Mar. - Oct. & 0.5 & 34 \\
\hline & $\mathrm{R} 4$ & 2001 & Mar. - Oct. & 0.5 & 30 \\
\hline & R5 & 2001 & Apr. - Oct. & 0.5 & 33 \\
\hline \multirow[t]{3}{*}{ Ino } & $\mathrm{R} 1+\mathrm{R} 2$ & 2000 & Jun. - Oct. & 1.0 & 26 \\
\hline & R1 & 2001 & Apr. - Oct. & 0.5 & 40 \\
\hline & R2 & 2001 & Apr. - Oct. & 0.5 & 33 \\
\hline Konomiyama & & 2000 & Mar. - Oct. & 1.0 & 28 \\
\hline
\end{tabular}

diversity data that had been taken in 1994-97 at Aburayama (Fukuoka City) by a transect monitoring method (Sasaki and Nakamura, 1995, 1996, 1997, 1998).

Data amalysis: In this paper, species richness obtained by $N$-time monthly surveys is expressed as $S$. Species richness obtained by $n$-time monthly surveys among $N$-time monthly surveys is expressed as $S n .{ } \mathrm{C} n$ is the number of combinations of monthly surveys. The maximum $S n$ in all combinations is represented as $S n m$.

In $S n m$, an index, $N n$ showing which months should be included in $n$-time surveys, was calculated as follows: because $N n$ is a binary function, $N n i=1$ represents that $i$ month is necessary to be included in $S n m$ and $N n i=0$ represents that $i$ month is not necessary. The $M n i$ index shows relative necessity of field survey at $i$-month in a year and is calculated as a value divided $N n i$ by $n$. If more than one Snm exist, Mni is further divided by the number of Snm.

\section{Results}

The species richness of leafhopper (S) was 25 to 42 (Table 1). The average number of species was most abundant in August (Fig. 1). In butterfly, the richness (S) was 40 to 47 (Table 1). The average numbers were higher from May to September than in other months 


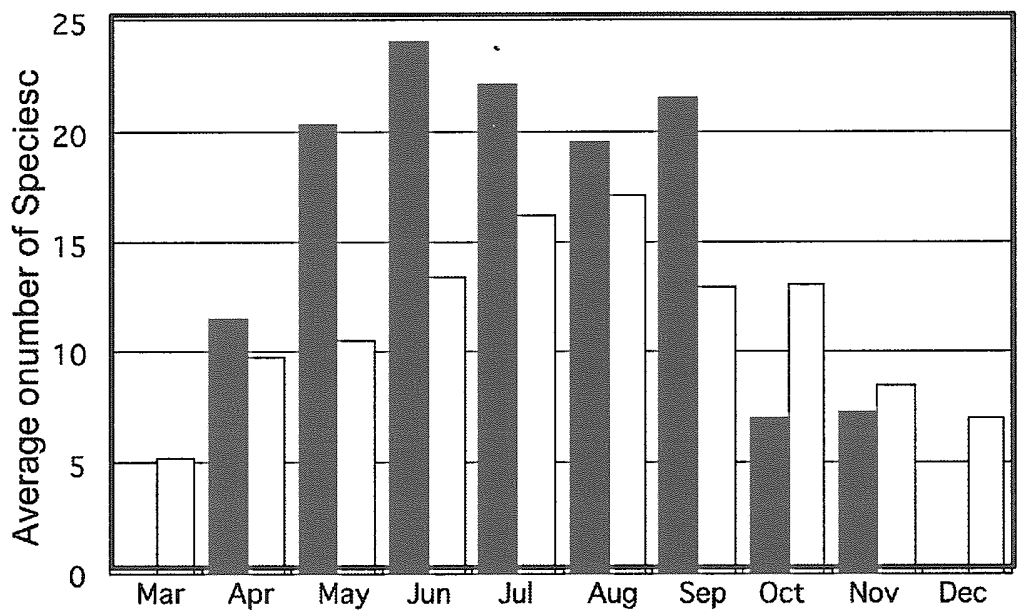

Fig.1. Average number of species collected. Open bar: leafhopper, solid bar: butterfly.

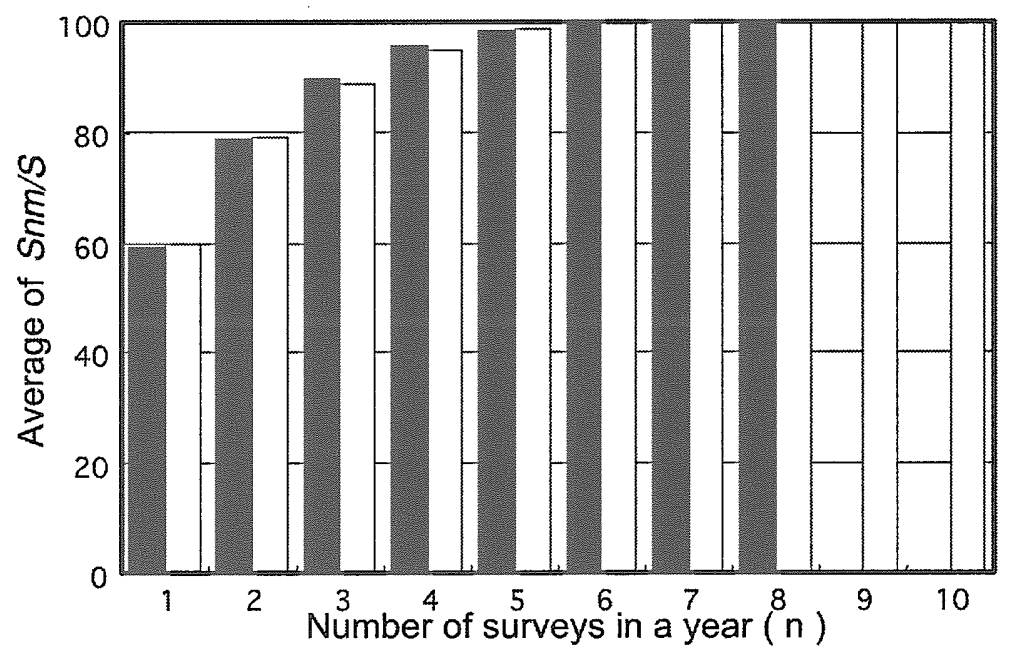

Fig.2. Average of $S n m / S$ and the number of surveys performed in a year. Open bar: leafhopper, solid bar: butterfly. 


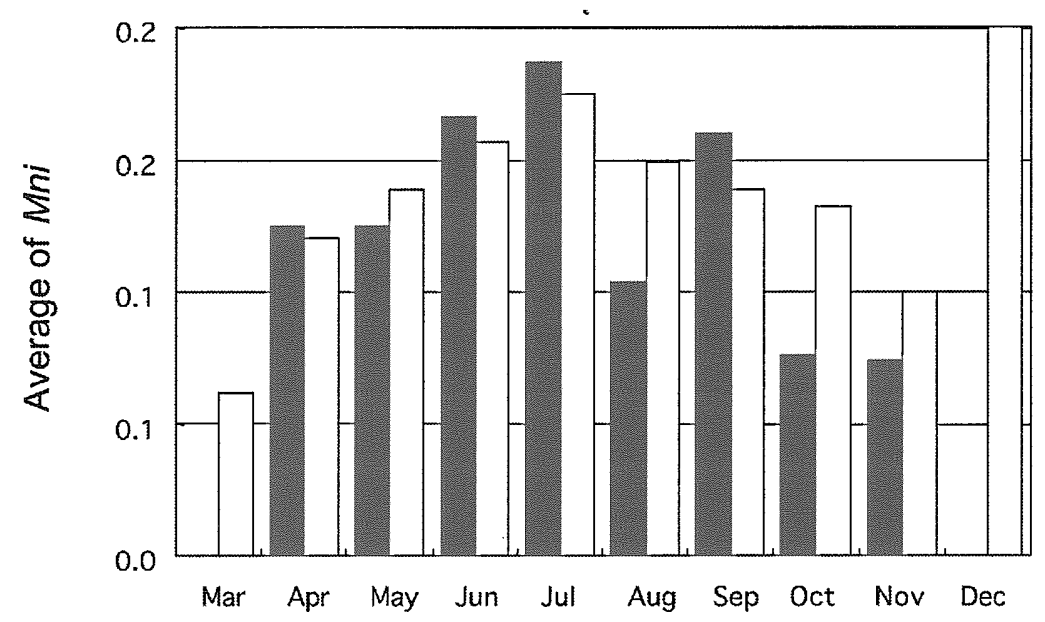

Fig.3. Average of Mni, which shows relative necessity of field survey at imonth in a year. Open bar: leafhopper, solid bar: butterfly.

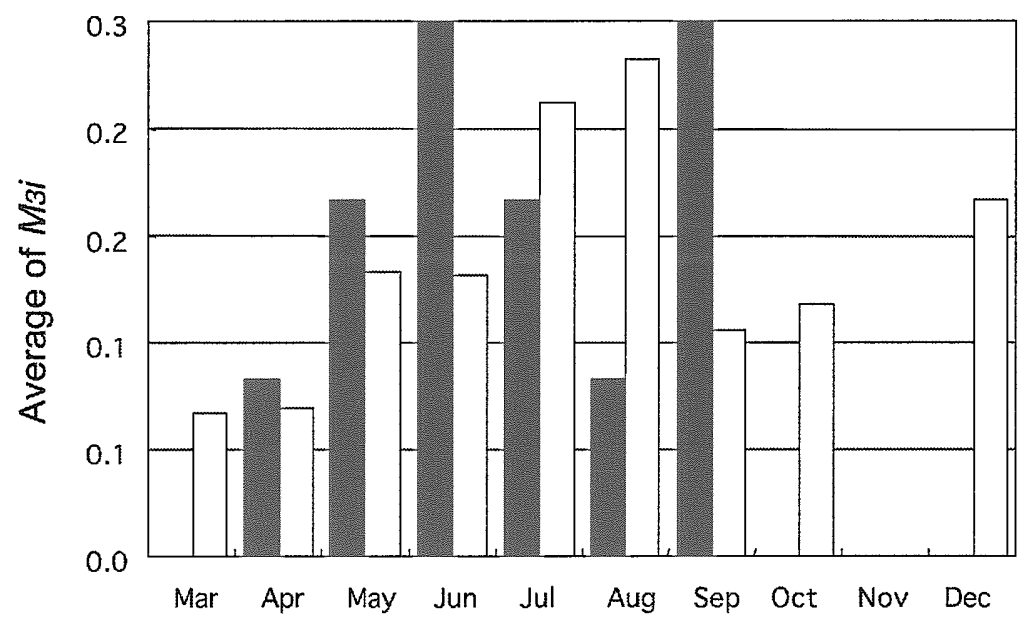

Fig.4. Average of $M 3 i$, which shows relative necessity of field survey at imonth in a year. Open bar: leafhopper, solid bar: butterfly. 
and there was a peak in June (Fig. 1).

There were 32 combinations at $6 \mathrm{Cn}, 64$ at $7 \mathrm{Cn}, 128$ at $8 \mathrm{Cn}, 256$ at $9 \mathrm{Cn}$, and 1023 at $10 \mathrm{C} n$. The average of $S n m / S$ was almost equal between leafhopper and butterfly regardless of the number of field surveys in a year (Fig. 2).

$S 3 m$ was 0.89 in leafhopper and 0.90 in butterfly. The average of the minimum $n$ that makes $S n m / S$ equal to 1 was 5.4 for leafhopper and 5.5 for butterfly. In order to assess the true species richness of leafhopper, December was the month that is most necessary to be included in a survey (Fig. 3). Similarly July was so for the survey of butterfly. In the case of 3-time field surveys, August was the most important month for the survey of leafhopper, and June and September were most important for butterfly (Fig. 4).

\section{Discussion}

The average of the minimum $n$ indicates that we have to survey six times in a year to assess the true species richness of leafhopper and butterfly. Therefore leafhopper should be surveyed in May, June, July, August, September, and December, of which the last one is the key month as indicated in Fig. 3. For butterfly, we should survey in April, May, June, July (key month), August, and September.

About $90 \%$ of true species richness of leafhopper and butterfly can be clarified by 3time field surveys. A combination of months to be surveyed was July-August-December for leafhopper and May-June-September or June-July-September for butterfly.

Although December was revealed to be the most required month to assess the species richness of leafhopper, the study sites surveyed in December were only Motooka R1 and $\mathrm{R} 2$ in 2000. In addition, these study sites were not surveyed in September and October. To fill the lack of field data in September and October, I summed up the data that were obtained in the 2000 and 2001 surveys at Motooka R1 and R2. In this case, a combination of months required to assess the true species richness was determined as April-May-June-July-AugustOctober or April-May-June-July-August-December. A combination of months required to assess the species richness by 3-time surveys was May-June-July or May-July-August.

The months required to assess the diversity of butterfly were quite similar to those for leafhopper during spring and early summer seasons, but they were different in autumn. This suggests an importance of field survey planning according to purposes of the general environmental assessment. Therefore, we should determine an optimal schedule of field surveys for given insect groups and for respective study sites, because the optimal schedule may vary with insect groups and study sites. 


\section{References}

Harin, J. L. \& D. L. Hawksworth, 1996. Preface. pp. 5-12, In Hawksworth, D. L. (ed.) Biodiversity: Measurement and Estimation. Chapman \& Hall, London.

Kamitani, S. \& A. Saito, 2001. Which cicadellid species (Homoptera) are difficult to find in a heterogeneous habitat? Esakia, (41): 27-36.

Kamitani, S. \& S. Urano, 2000. Species diversity and optimal sampling size of Auchenorrhyncha (Homoptera) in a homogeneous habitat. Esakia, (40): 87-94.

Sasaki, K. \& S. Nakamura, 1995. [Butterflies of Aburayama in 1994]. Ann. Rep. Aburayama, (1): 43-46. (In Japanese.)

Sasaki, K. \& S. Nakamura, 1996. [Butterflies of Aburayama in 1995]. Ann. Rep. Aburayama, (2): 31-35. (In Japanese.)

Sasaki, K. \& S. Nakamura, 1997. [Butterflies of Aburayama in 1996]. Ann. Rep. Aburayama, (3): 29-32. (In Japanese.)

Sasaki, K. \& S. Nakamura, 1998. [Butterflies of Aburayama in 1997]. Ann. Rep. Aburayama, (4): 15-18. (In Japanese.)

Yamamoto, M., 1998. [Route-census method]. pp. 29-43, In Imai, C. \& M. Ishii (ed.), $A$ Manual to Research Butterflies. Jap. Soc. Envir. Ent. Zool., Osaka. (In Japanese.) 


$$
\text { " }
$$

